\title{
Chronic disease and falls in community-dwelling Canadians over 65 years old: a population-based study exploring associations with number and pattern of chronic conditions
}

\author{
Kathryn M Sibley ${ }^{1,2}$, Jennifer Voth ${ }^{1,3}$, Sarah E Munce ${ }^{4}$, Sharon E Straus ${ }^{5,6}$ and Susan B Jaglal $1^{1,2,4^{*}}$
}

\begin{abstract}
Background: Falls and chronic disease are both important health issues in older adults. The objectives of this study were to quantify the prevalence of falls and multi-morbidity ( $\geq 2$ chronic conditions) in Canadian older adults; examine associations between falls and number of chronic conditions; and explore whether certain patterns of chronic disease were associated with a greater risk of falling.

Methods: Data were derived from the Canadian Community Health Survey- Healthy Aging. Primary outcomes from 16,357 community-dwelling adults aged 65 years and over were self-reported falls in the previous 12 months and presence of 13 chronic conditions. Prevalence estimates were calculated with normalized sampling weights, and hierarchical cluster analysis was used to identify clusters based on chronic condition patterns, and tested for association to falls with logistic regression.

Results: Overall prevalence of falling and multi-morbidity were $19.8 \%$ and $62.0 \%$ respectively. Fall risk was significantly greater in individuals with one, two, four, five and six or more chronic conditions relative to those with none (all $p<0.05)$. A seven-cluster model was selected, including groups with low prevalence of chronic disease, or high prevalence of hypertension and arthritis, visual impairment, hypertension, chronic obstructive pulmonary disease (COPD), diabetes, or heart disease and hypertension. Only the hypertension cluster (Odds Ratio $[O R]=1.2$ ) and COPD cluster $(O R=1.6)$ were significantly associated with increased falls relative to the low prevalence group.

Conclusions: Both the number and pattern of chronic conditions were related to falls. COPD emerged as a significant predictor of falls despite affecting a smaller proportion of respondents. Continued study is warranted to verify this association and determine how to incorporate consideration of chronic disease and multi-morbidity into fall risk assessments.
\end{abstract}

\section{Background}

Falls are a major health concern for older adults, often triggering a downward spiral in health that is associated with activity restriction [1], high health care costs [2] and long term care admission [3]. Many factors contribute to falls, and among these, a number of chronic conditions, including arthritis, diabetes and visual impairment, are associated with increased fall risk [4]. The falls literature has regarded such conditions as mediating factors, and when chronic

\footnotetext{
* Correspondence: susan.jaglal@utoronto.ca

${ }^{1}$ Toronto Rehabilitation Institute, University Health Network, Toronto, Canada ${ }^{2}$ Department of Physical Therapy, University of Toronto, Toronto, Canada Full list of author information is available at the end of the article
}

diseases are considered, it is often in the context of the effect of a single condition. For example, a recent systematic review on fall risk factors identified at least six chronic conditions independently associated with falls in a minimum of two prospective cohort studies, however they were all treated as independent risk factors and there was no indication whether chronic conditions were considered in multiple or combination [4]. In fact, the emerging older adult population is increasingly complex, and chronic disease is on the rise [5]. Approximately $92 \%$ of older adults have at least one chronic disease [5] and 65-85\% have two or more co-existing chronic diseases [6], commonly described as multi-morbidity [7]. Optimizing health service 
delivery for older adults requires a shift away from singledisease models of care [8]. However, current fall prevention guidelines [9] do not explicitly account for the role of chronic disease (either in single or multiple), and many of the practice guidelines for individual chronic diseases do not consider multi-morbidity or falls $[10,11]$. This may be due to the limited information on the association between total disease burden and falls from which to inform guidelines.

To date, only a few studies have investigated the association between multi-morbidity and falls [12-14]. For example, Lee et al. observed substantial co-occurrence of several chronic conditions and falls among 11,000 older adults, and increased prevalence of falling among those with a chronic disease than without [12]. In another study of 12,669 community-dwelling older adults receiving Medicare in the United States, Shumway-Cook et al. determined that the likelihood of having 1 or 2 or more falls in the previous year (relative to no falls) was associated with increasing number of comorbidities [13]. However, existing studies of falls and multi-morbidity have a number of limitations. First, any examination of "multi-morbidity" to date has been restricted to exploring the impact of simple disease counts on falls, and has not examined the influence of particular combinations of disease. While evidence to date suggests that number of chronic conditions is important, there may be an additional layer of importance related to falls as a function of the pattern of chronic conditions across individuals. Second, there has been extensive variation in both the number and type of chronic conditions considered across previous falls and multi-morbidity studies. Although there is no gold standard index of chronic disease, a recent systematic review on multi-morbidity indices recommended the inclusion of eight diagnoses based on overall prevalence in the population as a representative standard (arthritis, cancer, chronic obstructive pulmonary disease [COPD], diabetes, depression, heart disease or myocardial infarction, hypertension, stroke), as well as relevant or study-specific conditions [15]. Given the varied nature of aging and range of conditions associated with increased fall risk, a comprehensive approach to considering multi-morbidity in relation to falls is warranted.

Improved understanding of relationships between falls and chronic disease in older adults is needed to provide recommendations that will be of maximal use to clinicians who need to provide integrated care for complex patients. This study addressed gaps in the literature by exploring whether particular combinations of chronic disease were associated with falls in a recent Canadian populationbased sample. Chronic disease patterns were investigated with cluster analysis, which facilitated exploration of the complex array of conditions comprising "multi-morbidity", and whether particular patterns were associated with falls. The specific objectives were to quantify the prevalence of falls, individual chronic conditions and multi-morbidity in community-dwelling Canadians aged 65 years and older; examine associations between falls, individual chronic conditions, and number of chronic conditions; and explore whether clusters based on patterns of chronic conditions experienced elevated rates of falls.

\section{Methods}

This study was approved by the Research Ethics Board at the University of Toronto. Secondary data analyses were conducted using the Canadian Community Health Survey Healthy Aging, a population-based, cross-sectional survey conducted by Statistics Canada between December 2008 and November 2009. Details of the survey, including data sources and methodology, the questionnaire, and data accuracy are described online [16] and in a published report [17]. In brief, a multistage stratified cluster design sampling procedure based on the 2006 Census was used, and included people aged 45 or older living in private dwellings in all ten Canadian provinces. Individuals were excluded if they lived in the three territories, some remote regions, institutions, Indian reserves or Crown lands, military bases, or were full-time members of the Canadian Forces. Computerassisted personal interviewing was used to collect information about general health and well-being, physical activity, use of health care services, social participation, work and retirement transitions. The survey was completed by 30,865 individuals; an overall response rate of $74.4 \%$. Multiple quality control steps were used, including error detection by the computer-assisted interview software, validation with outcomes common in other Canadian population surveys, and external validation by federal and provincial partners.

This study includes data from 16,357 individuals aged 65 and over who answered the question, "in the past 12 months, did you have any falls?". Data for the present study were derived from questions throughout the survey and were collapsed or recategorized where appropriate. The primary outcome for this study was self-reported falls in the previous twelve months (binary: yes/ no). Secondary variables related to falls included number of falls, injuries related to falls, need for medical attention and hospitalizations resulting from falls. As per recommendations for measuring multi-morbidity, we included eight frequently reported chronic diseases (arthritis, cancer, chronic obstructive pulmonary disease [COPD], diabetes, depression, heart disease [angina or myocardial infarction], hypertension, stroke) and five study-specific chronic conditions with known associations to falls or hip fracture (dementia, osteoporosis, Parkinson's disease, urinary incontinence, and visual impairment [cataracts or glaucoma]) [4,18-20], all defined in the survey as lasting 6 months or more and diagnosed by a health professional. Presence or absence of each condition as well as total number of conditions was calculated. Individuals 
Table 1 Demographic and clinical characteristics

\begin{tabular}{|c|c|c|c|c|c|c|c|}
\hline Variable & $\begin{array}{l}\text { Total Sample } \\
\text { (weighted \%) }\end{array}$ & $\begin{array}{l}\text { Fallers } \\
\text { (weighted \%) }\end{array}$ & $\begin{array}{l}\text { Non-fallers } \\
\text { (weighted \%) }\end{array}$ & $\begin{array}{l}\text { Rao-Scott } X^{2} \\
\text { (weighted \& } \\
\text { boot-strapped) }\end{array}$ & $\mathbf{P}$ & $\begin{array}{l}\text { Fallers } 95 \% \\
\text { Cl for proportion }\end{array}$ & $\begin{array}{l}\text { Non-fallers } 95 \% \\
\mathrm{Cl} \text { for proportion }\end{array}$ \\
\hline Age (years) & & & & 63.4 & $<0.0001$ & & \\
\hline $65-74$ & 55.2 & 47.3 & 57.1 & & & $44.9-49.7$ & $56.5-57.7$ \\
\hline $75-84$ & 33.6 & 37.4 & 32.7 & & & $35.3-39.5$ & $32.2-33.2$ \\
\hline $85+$ & 11.2 & 15.3 & 10.2 & & & $14.0-16.7$ & $9.9-10.5$ \\
\hline Sex & & & & 28.2 & $<0.0001$ & & \\
\hline Male & 45.1 & 38.8 & 46.7 & & & $36.5-41.1$ & $46.1-47.3$ \\
\hline Female & 54.9 & 61.2 & 53.3 & & & $58.9-63.5$ & $52.7-53.9$ \\
\hline Married & & & & 41.2 & $<0.0001$ & & \\
\hline Yes & 63.4 & 56.1 & 65.2 & & & $53.5-58.7$ & $64.0-66.3$ \\
\hline No & 36.0 & 43.9 & 34.8 & & & $41.3-46.4$ & $33.7-36.0$ \\
\hline Living arrangement & & & & 24.4 & $<0.0001$ & & \\
\hline Alone & 29.3 & 34.5 & 28.0 & & & $32.1-36.9$ & $26.8-29.2$ \\
\hline With others & 64.8 & 60.4 & 65.9 & & & $57.9-62.8$ & $64.7-67.1$ \\
\hline Other & 5.9 & 5.1 & 6.1 & & & $3.9-6.4$ & $5.25-7.01$ \\
\hline Geographic setting & & & & 0.04 & 0.84 & & \\
\hline Urban & 78.5 & 78.3 & 78.6 & & & 75.3-81.4 & $76.4-80.8$ \\
\hline Rural & 21.5 & 21.7 & 21.4 & & & $18.6-24.7$ & 19.2-23.6 \\
\hline Mobility & & & & 258.7 & $<0.0001$ & & \\
\hline Walks independently & 87.5 & 76.1 & 90.3 & & & $74.2-78.1$ & 89.6-91.1 \\
\hline Walks with aid or support & 11.7 & 22.3 & 9.1 & & & $20.4-24.3$ & 8.4-9.9 \\
\hline Cannot walk & 0.7 & 1.5 & 0.5 & & & $0.9-2.1$ & $0.4-0.7$ \\
\hline ADL impairment & & & & 238.4 & $<0.0001$ & & \\
\hline None & 77.4 & 63.6 & 80.8 & & & $61.2-66.1$ & 79.7-81.8 \\
\hline Mild/Moderate & 20.1 & 30.9 & 17.4 & & & $28.5-33.3$ & $16.4-18.4$ \\
\hline Severe/Total & 2.6 & 5.5 & 1.8 & & & $4.4-6.6$ & $1.5-2.6$ \\
\hline Medication use & & & & 106.1 & $<0.0001$ & & \\
\hline$>4$ & 85.0 & 76.5 & 87.1 & & & 74.5-78.6 & $86.1-88.0$ \\
\hline$<=4$ & 15.0 & 23.5 & 12.9 & & & $21.5-25.5$ & $12.0-13.7$ \\
\hline Fear of falling & & & & 188.3 & $<0.0001$ & & \\
\hline Yes & 33.6 & 49.6 & 29.7 & & & $46.9-52.2$ & $28.4-31.0$ \\
\hline No & 66.4 & 50.4 & 70.3 & & & 47.7-53.1 & 69.0-71.6 \\
\hline Psychotropic medications & & & & 75.2 & $<0.0001$ & & \\
\hline Yes & 19.4 & 27.6 & 17.4 & & & 25.3-29.9 & $16.4-18.4$ \\
\hline No & 80.6 & 72.4 & 82.6 & & & $70.1-74.7$ & $81.6-83.6$ \\
\hline Vitamin D supplementation & & 42 & 38 & 7.8 & 0.0052 & & \\
\hline Yes & 39.4 & .8 & 6 & & & $40.1-45.5$ & 37.4-39.9 \\
\hline No & 60.6 & 57.2 & 61.4 & & & $54.5-59.9$ & $60.1-62.6$ \\
\hline
\end{tabular}

$\mathrm{ADL}=$ Activities of daily living.

were defined as having multi-morbidity if they had two or more chronic conditions. Clinical and demographic characteristics included age, sex, marital status, geographic setting, living arrangement, mobility, activities of daily living impairment, fear of falling, use of four or more medications, use of psychotropic medications (tranquilizers, antidepressants or sleeping pills), fear of falling, and vitamin D supplementation.

Analysis was performed with SAS version 9.3 (SAS Institute, Cary, NC). To account for the stratified 
survey sampling design, normalized sampling weights were applied to prevalence estimates and bootstrap weights were applied to variance calculations, using data provided by Statistics Canada. Descriptive statistics were calculated for all variables. Proportional differences in outcome variables between groups were compared with the Rao-Scott $\mathrm{X}^{2}$ test. Binary logistic regression modeled risk of falling as function of number of chronic conditions.

To explore whether some chronic disease patterns had a greater influence on falls than others, a two-step procedure was applied. Cluster analysis was used to identify meaningful sub-groups of individuals based on their responses to the chronic disease questions in the survey (binary indicators) [21]. Chronic conditions with very low prevalence $(<2.0 \%)$ were excluded from cluster analysis to minimize chaining (sequential joining into clusters) [22]. We used a hierarchical agglomerative clustering approach in which all individuals in the dataset are first treated as their own clusters, and are then merged into larger groupings based on a series of steps that attempt to minimize the variance within clusters so that the members in each cluster are as similar to each other as possible and as different as possible from members in other groupings $[22,23]$. A hierarchical approach attempts to find the optimal solution when the true number of clusters is not known [22], and we used Ward's minimum variance method [24], which defines the distance between clusters as the increase in sum of squares within clusters after each step and summed over all variables, to identify the optimal number of groupings among participants using the jaccard dissimilarity coefficient. Ward's method was chosen because it performs well in simulation studies comparing clustering methods and because it tends to produce welldistributed clusters [22,25]. The appropriate number of clusters was decided by consulting each agglomeration schedule, noting local peaks in the pseudo-F statistic that corresponded with decreases in pseudo-t at each subsequent step, and examining common peaks across each method [26]. The dendogram for each method was also consulted. The final cluster solution was validated first by comparing the results to solutions generated by the average linkage and centroid hierarchical clustering methods - two complementary clustering methods that define the distances between clusters based on average distance between pairs of objects between clusters (average linkage) and squared Euclidean distance between mean vectors (centroid) [22] - and then by running separate cluster analyses on each half of the randomly divided dataset to investigate the stability of the final solution. Binary logistic regression was then used to determine whether any of the clusters were significantly associated with falls (controlling for age and gender as covariates). Odds ratios (ORs) are reported for significant associations.

\section{Results}

Prevalence of falls, individual chronic conditions and multi-morbidity

Selected clinical and demographic characteristics are presented in Table 1. The overall proportion of individuals who reported falling in the previous year was $19.8 \%$. Detailed fall characteristics are presented in Table 2 . In summary, among the fallers, $63.3 \%$ fell once in the previous year, while $36.7 \%$ fell more than once. Thirty-five percent reported no serious injury as a result of their fall(s). Among those who experienced some injury, $29.3 \%$ sought medical attention, and $7.8 \%$ reported being hospitalized. Sixty-two percent of respondents had multi-morbidity, while $23.8 \%$ of respondents had a single chronic condition and $14.2 \%$ had no chronic condition. The prevalence of specific individual chronic conditions is presented in Table 3. All thirteen chronic conditions considered were observed.

\section{Associations between falls, individual chronic conditions and number of chronic conditions}

Falls in the previous twelve months were significantly lower among people with no chronic conditions (11.4\%)

\section{Table 2 Fall characteristics}

\begin{tabular}{ll}
\hline Variable & Weighted \% \\
\hline Number of falls & 63.3 \\
1 & 19.0 \\
2 & 8.1 \\
3 & 3.7 \\
4 & 5.4 \\
$>=5$ & \\
Most serious injuries resulting from fall(s) & 35.1 \\
No serious injury & 21.2 \\
Bruises & 9.9 \\
Sprain/strain & 8.6 \\
Discomfort & 8.1 \\
Other & 5.6 \\
Cuts & 3.5 \\
Fracture of arm or wrist & 3.0 \\
Head injury & 2.3 \\
Fracture of leg & 1.4 \\
Fracture of back/vertebra & 1.2 \\
Fracture of hip & \\
Medical attention sought & 70.7 \\
Yes & \\
No & \\
Hospitalization after fall & \\
Yes & \\
\hline & \\
\hline &
\end{tabular}


Table 3 Chronic conditions and falls

\begin{tabular}{|c|c|c|c|c|c|c|c|}
\hline Condition & $\begin{array}{l}\text { Prevalence } \\
\text { (weighted \%) }\end{array}$ & $\begin{array}{l}\% \text { of people with } \\
\text { condition who fell } \\
\text { (weighted \%) }\end{array}$ & $\begin{array}{l}\% \text { of people without } \\
\text { condition who fell } \\
\text { (weighted \%) }\end{array}$ & $\begin{array}{l}\text { Rao-Scott X2 } \\
\text { (weighted \& } \\
\text { boot-strapped) }\end{array}$ & $P$ value & $\begin{array}{l}95 \% \mathrm{Cl} \text { for } \% \text { of } \\
\text { people with } \\
\text { condition } \\
\text { who fell }\end{array}$ & $\begin{array}{l}95 \% \mathrm{Cl} \text { for } \% \text { of } \\
\text { people without } \\
\text { condition } \\
\text { who fell }\end{array}$ \\
\hline Hypertension & 50.2 & 21.4 & 18.3 & 10.8 & 0.01 & $20.1-22.7$ & 16.9-19.6 \\
\hline Arthritis & 43.4 & 24.4 & 16.3 & 82.9 & $<0.0001$ & $22.9-25.9$ & $15.1-17.4$ \\
\hline Vision impairment & 27.8 & 24.1 & 18.2 & 32.6 & $<0.0001$ & $22.3-25.9$ & $17.1-19.3$ \\
\hline Heart disease & 22.6 & 24.4 & 18.5 & 30.3 & $<0.0001$ & $22.5-26.4$ & 17.5-19.6 \\
\hline Osteoporosis & 18.1 & 25.5 & 18.5 & 36.8 & $<0.0001$ & $23.2-27.7$ & $17.5-19.5$ \\
\hline Diabetes & 17.2 & 23.8 & 19.0 & 17.1 & $<0.0001$ & 21.6-26.1 & $18.0-20.0$ \\
\hline Incontinence & 11.7 & 28.1 & 18.7 & 49.7 & $<0.0001$ & 25.4-30.7 & 17.7-19.8 \\
\hline COPD & 8.8 & 25.5 & 19.3 & 18.1 & $<0.0001$ & $22.4-28.6$ & $18.3-20.2$ \\
\hline Cancer & 5.5 & 22.9 & 19.6 & 2.2 & 0.14 & $18.4-27.4$ & $18.7-20.6$ \\
\hline Depression & 5.1 & 36.0 & 19.0 & 52.4 & $<0.0001$ & $31.0-41.1$ & 18.0-19.9 \\
\hline Stroke & 4.2 & 36.8 & 19.1 & 72.9 & $<0.0001$ & $32.0-41.6$ & $18.1-20.0$ \\
\hline Dementia & 1.6 & 38.5 & 19.5 & 31.3 & $<0.0001$ & $30.4-46.6$ & 18.6-20.5 \\
\hline Parkinson's disease & 0.8 & 30.8 & 19.8 & 4.7 & 0.029 & $19.5-42.1$ & $18.8-20.5$ \\
\hline
\end{tabular}

$\mathrm{COPD}=$ Chronic obstructive pulmonary disease.

compared to those with any chronic condition $\left(21.2 \%, \mathrm{X}^{2}\right.$ $[1]=60.0, p<0.0001$ ); fall rates ranged from $21.4-38.5 \%$ in those with a chronic condition (Table 3 ). Risk of falling increased as a function of the number of chronic conditions (Table 4), and was significantly elevated among individuals with one, two, four, five and six or more chronic conditions relative to those with no chronic conditions (all $\mathrm{p}<0.05$ ).

\section{Influence of specific chronic disease patterns on falls}

Dementia and Parkinson's Disease were omitted from the cluster analysis due to low prevalence $(<2 \%$ each). Ward's method suggested that a seven-cluster solution best fit the data, which was supported by visual inspection of the dendogram (Additional file 1). The sevencluster solution was validated by replication with the centroid method, while the average linkage method suggested a highly similar cluster pattern. When the data were split into two random halves, Ward's method also indicated that a seven-cluster solution fit both halves. As such, the robust seven-cluster pattern was selected for the final solution.

Prevalence of each chronic condition, clinical and demographic characteristics are presented by cluster in Table 5 . All chronic conditions were represented in each cluster, although each cluster was dominated by a high prevalence $(>70 \%)$ of one or two conditions, or in one case: relatively low prevalence of all conditions. As such, cluster \#1 (28.8\% of sample) was labeled "low chronic disease"; cluster \#2 (12.3\%): "hypertension and arthritis"; cluster \#3 (12.6\%): "visual impairment"; cluster \#4 (19.6 \%): "hypertension"; cluster \#5 (5.7\%): “COPD”; cluster \#6 (11.6\%): “diabetes"; and cluster \#7 (9.4\%) was labeled "heart disease and hypertension".

Selected clinical and demographic characteristics are presented for each cluster in Table 6. Relative to cluster \#1 ("low chronic disease"), the remaining clusters tended to be older, female, require more mobility assistance, have greater impairment in activities of daily living, and took more medications $(\mathrm{p}<0.01)$. Logistic regression results revealed that only clusters \#4 (hypertension) and \#5 (COPD) were significantly associated with increased risk of falls relative to cluster $\# 1(\mathrm{OR}=1.2, \mathrm{p}=0.048$ and $\mathrm{OR}=1.6$, $\mathrm{p}=0.03$, respectively; Table 7).

\section{Discussion}

This study demonstrated that fall incidence among community-dwelling older Canadians is highly linked to the presence of chronic disease. Fall rates were significantly higher among individuals with a chronic condition compared to those without, and all individual chronic conditions with the exception of cancer were associated with increased prevalence of falls. Importantly, both number and type of chronic condition played a role in falls. With respect to number, fall rates increased linearly with the number of conditions. With respect to type, when considering combinations of chronic disease identified by cluster analysis, though some conditions were relatively evenly distributed across all clusters (e.g. cancer) and others were concentrated primarily in one cluster (e.g. diabetes), two groups of individuals were associated with increased risk of falls relative to the group with low prevalence of chronic disease: "hypertension" and "COPD". 
Table 4 Logistic regression results for number of chronic conditions and falls

\begin{tabular}{llll}
\hline Number of chronic conditions & $\mathbf{X}^{\mathbf{2}}$ & $\mathbf{P}$ value & OR \\
\hline 0 & Reference & & \\
1 & 9.1 & 0.03 & 1.3 \\
2 & 3.7 & 0.05 & 1.4 \\
3 & 0.1 & 0.7 & 1.7 \\
4 & 5.1 & 0.02 & 2.0 \\
5 & 4.6 & 0.03 & 2.1 \\
6 or more & 13.4 & 0.003 & 2.7 \\
\hline
\end{tabular}

The finding that falls were related to the total disease burden supports previous studies showing increased risk of falling with multi-morbidity $[12,13]$. In particular, the observed linear trend between the prevalence of falling and number of chronic conditions substantiates the results of Lawlor et al. [14], who observed a linear relationship between the prevalence of falling in the previous year and the number of simultaneously present chronic diseases among communitydwelling women aged 60-79 years. Collectively, these results suggest an additive effect of chronic disease on fall risk, irrespective of the specific condition. While such information has some clinical value, the inability to speak to the influence of specific conditions is a limitation. The cluster analysis approach is a key strength of the current study, as it facilitated the exploration of the question about whether particular chronic disease combinations were associated with falls. Indeed, while our cluster analysis suggested that Canadian community-dwelling adults aged
65 years and older comprised seven distinct clusters based on chronic disease status, logistic regression revealed that not all of them were significantly associated with falls.

Interestingly, the dominating conditions in each of the two clusters significantly associated with falls - hypertension and COPD - were included in our consideration of multi-morbidity as a result of multi-morbidity measurement recommendations [15], not because of their specific association to falls. And yet, our finding that these clusters were associated with a significant increase in fall risk is supported by the literature. With respect to hypertension, there are several potential linking mechanisms to falls related to both the condition itself and treatment side effects known to induce orthostatic hypotension. Thiazide, prescribed as an anti-hypertensive medication, was associated with increased fall risk in the first three weeks after prescription in one prospective study of 56,000 older adults in primary care $[27,28]$. Emerging evidence also suggests that hypertension itself is a risk factor for orthostatic hypotension [29] and is related to falls. A recent prospective population study of 766 community-dwelling older adults determined that people with uncontrolled hypertension and orthostatic hypotension were 2.5 times more likely to have recurrent falls than those with uncontrolled hypertension and no orthostatic hypotension [30]. Similarly, fall risk has not traditionally been the primary concern for people with COPD, but new evidence demonstrates that this population has both increased prevalence of falls [31,32] as well as dysfunction in physiological risk factors for falls, such as impaired postural control [33]. While the specific mechanisms through which COPD acts on falls are not

Table 5 Prevalence of chronic conditions, demographic and clinical characteristics by cluster

\begin{tabular}{|c|c|c|c|c|c|c|c|}
\hline Cluster Number & 1 & 2 & 3 & 4 & 5 & 6 & 7 \\
\hline Label & $\begin{array}{l}\text { Low chronic } \\
\text { disease }\end{array}$ & $\begin{array}{l}\text { Hypertension and } \\
\text { arthritis }\end{array}$ & $\begin{array}{l}\text { Visual } \\
\text { impairment }\end{array}$ & Hypertension & COPD & Diabetes & $\begin{array}{l}\text { Heart disease and } \\
\text { hypertension }\end{array}$ \\
\hline \multicolumn{8}{|c|}{ Weighted $\%$ with condition } \\
\hline Arthritis & 33.5 & 70.6 & 46.0 & 35.8 & 59.6 & 45.1 & 38.7 \\
\hline Osteoporosis & 3.8 & 29.4 & 1.1 & 12.6 & 16.2 & 8.5 & 1.8 \\
\hline Hypertension & 4.4 & 100.0 & 51.6 & 96.8 & 51.7 & 61.8 & 84.5 \\
\hline Diabetes & 0.6 & 8.2 & 6.3 & 2.6 & 18.8 & 100.0 & 22.6 \\
\hline Stroke & 0.9 & 5.9 & 1.6 & 8.9 & 5.1 & 5.7 & 2.8 \\
\hline COPD & 2.1 & 5.9 & 2.6 & 1.6 & 99.1 & 4.0 & 7.6 \\
\hline $\begin{array}{l}\text { Urinary } \\
\text { incontinence }\end{array}$ & 12.0 & 12.6 & 8.1 & 13.6 & 14.3 & 14.9 & 5.3 \\
\hline $\begin{array}{l}\text { Vision } \\
\text { impairment }\end{array}$ & 4.2 & 37.4 & 89.4 & 9.5 & 38.9 & 21.7 & 44.1 \\
\hline Heart disease & 16.5 & 23.8 & 2.6 & 3.8 & 30.0 & 23.3 & 100.0 \\
\hline Cancer & 8.8 & 0.9 & 1.4 & 4.9 & 5.5 & 8.3 & 4.1 \\
\hline Depression & 0.9 & 5.7 & 17.6 & 1.3 & 7.9 & 7.8 & 3.2 \\
\hline
\end{tabular}

COPD $=$ Chronic Obstructive Pulmonary Disease. 
Table 6 Clinical and demographic conditions by cluster

\begin{tabular}{|c|c|c|c|c|c|c|c|c|c|}
\hline Cluster Number & 1 & 2 & 3 & 4 & 5 & 6 & 7 & Rao-Scott $X^{2}$ & $P$ value \\
\hline Label & Low chronic disease & $\begin{array}{l}\text { Hypertension } \\
\text { and arthritis }\end{array}$ & $\begin{array}{l}\text { Visual } \\
\text { impairment }\end{array}$ & Hypertension & COPD & Diabetes & $\begin{array}{l}\text { Heart disease } \\
\text { and hypertension }\end{array}$ & $\begin{array}{l}\text { (weighted \& } \\
\text { boot-strapped) }\end{array}$ & \\
\hline Age (years) & & & & & & & & 148.3 & $<0.0001$ \\
\hline $65-74$ & 62.6 & 46.9 & 49.3 & 56.4 & 52.3 & 58.5 & 46.0 & & \\
\hline $75-84$ & 27.5 & 37.7 & 37.9 & 33.9 & 35.7 & 33.4 & 39.4 & & \\
\hline $85+$ & 9.9 & 15.4 & 12.8 & 9.7 & 12.0 & 8.1 & 14.3 & & \\
\hline Sex & & & & & & & & 486.4 & $<0.0001$ \\
\hline Male & 53.4 & 13.6 & 41.9 & 42.6 & 46.7 & 54.6 & 58.3 & & \\
\hline Female & 46.6 & 86.4 & 58.1 & 57.4 & 53.3 & 45.4 & 41.7 & & \\
\hline Married & & & & & & & & 98.9 & $<0.0001$ \\
\hline Yes & 67.8 & 51.0 & 61.1 & 66.5 & 63.2 & 65.0 & 60.8 & & \\
\hline No & 32.2 & 49.0 & 38.9 & 33.5 & 36.8 & 35.0 & 39.2 & & \\
\hline Living arrangement & & & & & & & & 63.3 & $<0.0001$ \\
\hline Alone & 27.0 & 37.2 & 32.2 & 26.9 & 30.8 & 25.9 & 30.0 & & \\
\hline With others & 68.2 & 55.5 & 62.1 & 67.1 & 64.4 & 65.9 & 64.0 & & \\
\hline Other & 4.8 & 7.2 & 5.7 & 6.0 & 4.8 & 8.2 & 6.0 & & \\
\hline Geographic setting & & & & & & & & 15.8 & 0.015 \\
\hline Urban & 78.7 & 82.2 & 80.4 & 77.9 & 76.0 & 77.9 & 74.6 & & \\
\hline Rural & 21.3 & 17.8 & 19.6 & 22.1 & 24.0 & 22.1 & 25.4 & & \\
\hline Current mobility status & & & & & & & & 210.6 & $<0.0001$ \\
\hline Walks independently & 92.5 & 81.2 & 89.9 & 89.1 & 78.4 & 83.2 & 85.1 & & \\
\hline Walks with aid or support & 7.1 & 18.1 & 9.6 & 10.3 & 19.6 & 15.1 & 14.5 & & \\
\hline Cannot walk & 0.4 & 0.7 & 0.5 & 0.6 & 2.0 & 1.7 & 0.4 & & \\
\hline Current ADL impairment status & & & & & & & & 153.2 & $<0.0001$ \\
\hline None & 84.0 & 67.9 & 77.8 & 79.1 & 68.0 & 74.8 & 74.1 & & \\
\hline Mild/Moderate & 14.3 & 29.4 & 20.0 & 18.5 & 26.6 & 21.9 & 23.8 & & \\
\hline Severe/Total & 1.7 & 3.7 & 2.2 & 2.4 & 5.4 & 3.2 & 2.1 & & \\
\hline Current number of medications & & & & & & & & 408.8 & $<0.0001$ \\
\hline$<4$ & 94.4 & 80.5 & 85.7 & 88.0 & 69.3 & 80.1 & 70.1 & & \\
\hline$>=4$ & 5.6 & 19.5 & 14.3 & 12.0 & 30.7 & 19.9 & 29.9 & & \\
\hline Fear of falling & & & & & & & & 191.1 & $<0.0001$ \\
\hline Yes & 24.8 & 48.3 & 37.6 & 31.4 & 39.6 & 36.6 & 33.9 & & \\
\hline No & 75.2 & 51.7 & 62.4 & 68.6 & 60.4 & 63.4 & 66.1 & & \\
\hline
\end{tabular}


Table 6 Clinical and demographic conditions by cluster (Continued)

\begin{tabular}{|c|c|c|c|c|c|c|c|c|c|}
\hline Psychotropic medications & & & & & & & & 75.9 & $<0.0001$ \\
\hline Yes & 14.2 & 25.4 & 23.8 & 17.6 & 28.0 & 19.6 & 22.3 & & \\
\hline No & 85.8 & 74.6 & 76.2 & 82.4 & 72.0 & 82.4 & 77.7 & & \\
\hline Vitamin D supplementation & & & & & & & & 7.8 & 0.0052 \\
\hline Yes & 35.5 & 63.5 & 40.4 & 39.0 & 38.1 & 31.6 & 30.0 & & \\
\hline No & 64.5 & 36.5 & 59.6 & 61.0 & 61.9 & 68.4 & 70.0 & & \\
\hline
\end{tabular}

$\mathrm{ADL}=$ Activities of daily living. 


$\begin{aligned} & \text { Table } 7 \text { Logistic regression results for chronic condition } \\
& \text { clusters and fall risk* }\end{aligned}$
\begin{tabular}{lllll}
\hline Cluster & Label & $\mathbf{X}^{\mathbf{2}}$ & $\mathbf{P}$ & $\begin{array}{l}\text { Odds } \\
\text { Ratio }\end{array}$ \\
\hline$\# 1$ & "Low chronic disease" & Reference & & \\
$\# 2$ & "Hypertension and arthritis" & 0.1 & 0.8 & 1.3 \\
$\# 3$ & "Visual impairment" & 1.6 & 0.22 & 1.2 \\
\#4 & "Hypertension" & $\mathbf{3 . 9}$ & $\mathbf{0 . 0 4 8}$ & $\mathbf{1 . 2}$ \\
\#5 & "COPD" & $\mathbf{4 . 9}$ & $\mathbf{0 . 0 3}$ & $\mathbf{1 . 6}$ \\
$\# 6$ & "Diabetes" & 2.1 & 0.1 & 1.5 \\
$\# 7$ & "Heart disease and & 3.7 & 0.06 & 1.3 \\
& hypertension" & & &
\end{tabular}

${ }^{*}$ Controlling for age and gender.

$\mathrm{COPD}=$ Chronic Obstructive Pulmonary Disease

fully understood, skeletal muscle dysfunction and cerebral hypoxemia have been postulated as contributing factors [32]. We also note that while hypertension was the most prevalent chronic condition overall (50.2\%) and the "hypertension" cluster was second in size only to the "low chronic disease" group, COPD prevalence was $8.8 \%$ overall and the "COPD" cluster was the smallest of the seven. As such, although COPD affected a relatively small proportion of individuals, the fact that it still emerged as a significant predictor of falls suggests it had a major impact on these people with respect to fall risk. That said, it is important to note that most chronic conditions individually had an effect on falls, and even though some may not have emerged as key drivers of chronic disease clusters across the population (stroke, for example), the fall risk associated with those conditions should not be understated.

Our study has a number of implications for clinical practice. First, given the differences in fall rates between individuals with and without chronic disease, the data underline differences within the community-dwelling older adult population with regard to falls, and that both the presence of specific chronic diseases and the number of conditions affecting an individual contribute to fall risk. Although current fall prevention guidelines [9] do not explicitly account for the role of chronic disease or multi-morbidity, clinicians may find this useful to consider when adapting these guidelines for individual patients. Second, the inherent challenges associated with managing multiple conditions require complementary strategies, and self-management approaches for older adults may offer additional opportunities to promote function and independence [34]. Although falls are episodic in nature, fall prevention requires sustained effort - similar to chronic disease management strategies - and many behaviors, such as exercise and medication monitoring, can benefit multiple conditions.

Many of the trends observed in this Canadian populationbased analysis were lower than previous reports. The total fall prevalence rate of $19.8 \%$ was slightly lower than a similar American population-based retrospective study that reported falls among $22 \%$ of older adults on Medicare living in the community [13]. Taken together, the mounting population-based data suggests that the commonly reported statistic that one in three older adults fall each year [35-37] may no longer be accurate. The prevalence of chronic disease in the present sample was also lower than other studies, occurring in $76 \%$ of older adults and multimorbidity occurring in $62 \%$. In contrast, American data estimates chronic disease in over $90 \%$ of communitydwelling older adults [5], and our observed multimorbidity rate was lower than the range reported in a recent systematic review of aging with multi-morbidity [6]. Although it could be interpreted that the present dataset may constitute a healthier population, between-study variations in the number of and specific chronic conditions considered may have contributed to some of these differences [38]. Comparison of chronic disease clusters between the current and previous analyses is also limited by the variation in populations and conditions considered across studies. While our analysis suggested that seven clusters best fit the data, Marengoni et al. [39] identified five clusters of multi-morbidity patterns in communitydwellers aged 77 years and over. While we are not aware of any other studies attempting to relate specific chronic disease patterns to falls in older adults, $\mathrm{Vu}$ et al. [40] explored chronic disease clusters in community-dwelling adults aged 65 and over who were hospitalized for a fall and identified five clusters. Unfortunately, it is not possible to make between-study cluster comparisons as all studies considered different numbers and type of chronic conditions.

Fall rates for many of the individual chronic conditions were also lower than previous reports (i.e. arthritis [41], visual impairment [18], diabetes [42], COPD [31], Parkinson's disease [19], cancer [43], and urinary incontinence [20]), although variations in fall reporting methods, diagnostic criteria and disease severity may have accounted for this. Interestingly, we were unable to locate any peerreviewed literature describing fall rates in people with osteoporosis. While many papers have discussed increased fall risk and the implications for hip fracture in this population, there appears to be a need for additional definitive research in this area.

Although the population-based analysis is a strength of this study, there are a number of limitations. As the survey was cross-sectional, cause-and-effect cannot be determined. All variables were derived from self-report data, not objective measures. Falls were identified by retrospective recall over the previous twelve months. Although other methods of fall reporting are more accurate [44,45], 12month recall is representative of clinical practice and is the method advocated for assessing fall risk in published fall prevention guidelines [9]. Falls were not defined for survey participants, which could have variations in interpretation 
of what constitutes a fall, and additional inaccuracies in the self-report data. The fear of falling variable was limited to a dichotomous question, which has been criticized for lacking detail and sensitivity [46]. A limitation common across multi-morbidity studies is the arbitrary selection of conditions included, and given the nature of the secondary analysis, we were not able to apply more standardized classifications of multi-morbidity [47]. The survey did not include evaluation of some key fall risk factors (such as balance), the use of particular medications and only considered current mobility status, disability, medication use and living arrangement (which may or may not have been the same at the time of the fall), so we were unable to adjust for these factors in our model.

\section{Conclusions}

These data illustrate the complex interplay between chronic disease and falls in older adults, highlighting the need for coordinated management of these health issues. While additional study is necessary to corroborate these findings, clinicians may consider multi-morbidity, hypertension, and COPD as particular 'red flags' for fall risk. Continued work is required to consider if and how chronic disease should be incorporated into fall prevention guidelines. In light of the emerging quantity and complexity of the aging population, collaborative efforts are required to optimize evidence-based care models of health service delivery for these individuals.

\section{Additional file}

\section{Additional file 1: Dendogram illustrating the seven-group cluster} solution selected for the present study (circles), using Ward's minimum variance method. The dendogram illustrates relationships of dissimilarity (reflected by the semi-partial r-squared of the Jaccard dissimiliarity coefficient, vertical axis) from 16,357 individuals (horizontal axis) based on their patterns of binary response to eleven self-reported chronic conditions (excluding Parkinson's disease and Dementia).

\section{Abbreviations}

COPD: Chronic obstructive pulmonary disease; OR: Odds ratios.

\section{Competing interests}

The authors declare that they have no competing interests.

\section{Authors' contributions}

KMS conceived of the study, designed the study, obtained ethics approval, conducted the analysis and wrote the manuscript. JV participated in study design, data analysis and interpretation, and manuscript writing. SEM participated in study design, data analysis and interpretation, and manuscript writing. SES participated in data analysis and interpretation and contributed to manuscript writing. SBJ participated in study conception, design, analysis interpretation and manuscript writing. All authors read and approved the final manuscript.

\section{Acknowledgements}

We acknowledge the support of the Statistics Canada Research Data Centre for facilitating data access, and the Toronto Rehabilitation Institute- University Health Network who received funding under the Provincial Rehabilitation Research Program from the Ministry of Health and Long Term Care in
Ontario. While the research and analysis are based on data from Statistics Canada, the opinions expressed do not represent the views of Statistics Canada.

\section{Author details}

${ }^{1}$ Toronto Rehabilitation Institute, University Health Network, Toronto, Canada. ${ }^{2}$ Department of Physical Therapy, University of Toronto, Toronto, Canada. ${ }^{3}$ Department of Psychology, University of Windsor, Windsor, Canada. ${ }^{4}$ Institute of Health Policy, Management and Evaluation, University of Toronto, Toronto, Canada. 'Li-Ka-Shing Knowledge Institute, St. Michael's Hospital, Toronto, Canada. ${ }^{6}$ Department of Medicine, University of Toronto, Toronto, Canada.

Received: 13 September 2013 Accepted: 11 February 2014

Published: 14 February 2014

\section{References}

1. Fletcher PC, Guthrie DM, Berg K, Hirdes JP: Risk factors for restriction in activity associated with fear of falling among seniors within the community. J Patient Saf 2010, 6:187-191.

2. SMARTRISK: The Economic Burden of Injury in Canada. In Book The Economic Burden of Injury in Canada. City: SMARTRISK; 2009.

3. Tinetti ME, Williams CS: Falls, injuries due to falls, and the risk of admission to a nursing home. N Engl J Med 1997, 337:1279-1284.

4. Tinetti ME, Kumar C: The patient who falls: "It"s always a trade-off". JAMA 2010, 303:258-266.

5. Hung W, Ross J, Boockvar K, Siu A: Recent trends in chronic disease, impairment and disability among older adults in the United States. BMC Geriatrics 2011, 11:47

6. Marengoni A, Angleman S, Melis R, Mangialasche F, Karp A, Garmen A, Meinow B, Fratiglioni L: Aging with multimorbidity: A systematic review of the literature. Ageing Research Reviews 2011, 10:430-439.

7. van den Akker M, Buntinx F, Knottnerus JA: Comorbidity or multimorbidity. European Journal of General Practice 1996, 2:65-70.

8. Boyd CM, Ritchie CS, Tipton EF, Studenski SA, Wieland D: From Bedside to Bench: summary from the American Geriatrics Society/National Institute on Aging Research Conference on Comorbidity and Multiple Morbidity in Older Adults. Aging Clinical and Experimental Research 2008, 20:181-188.

9. Panel on Prevention of Falls in Older Persons, American Geriatrics Society and British Geriatrics Society: Summary of the Updated American Geriatrics Society/British Geriatrics Society clinical practice guideline for prevention of falls in older persons. J Am Geriatr Soc 2011, 59:148-157.

10. Smith SM, Soubhi H, Fortin M, Hudon C, O'Dowd T: Managing patients with multimorbidity: systematic review of interventions in primary care and community settings. BMJ 2012, 345:e5205.

11. Mutasingwa DR, Ge H, Upshur RE: How applicable are clinical practice guidelines to elderly patients with comorbidities? Can Fam Physician 2011, 57:e253-e262.

12. Lee PG, Cigolle C, Blaum C: The Co-Occurrence of Chronic Diseases and Geriatric Syndromes: The Health and Retirement Study. J Am Geriatr Soc 2009, 57:511-516.

13. Shumway-Cook A, Ciol MA, Hoffman J, Dudgeon BJ, Yorkston K, Chan L: Falls in the Medicare Population: Incidence, Associated Factors, and Impact on Health Care. Phys Ther 2009, 89:324-332.

14. Lawlor DA, Patel R, Ebrahim S: Association between falls in elderly women and chronic diseases and drug use: cross sectional study. BMJ 2003, 327:712-717.

15. Diederichs $C$, Berger K, Bartels DB: The measurement of multiple chronic diseases-a systematic review on existing multimorbidity indices. J Gerontol A Biol Sci Med Sci 2011, 66:301-311.

16. Canadian Community Health Survey - Healthy Aging (CCHS). [http://www23. statcan.gc.ca/imdb/p2SV.pl?Function=getSurvey\&SDDS=5146\&ltem _ ld=47962\&lang=en].

17. Statistics Canada: Canadian Community Health Survey (CCHS) - Healthy Aging -2008/2009, User Guide. In Book Canadian Community Health Survey (CCHS) - Healthy Aging -2008/2009, User Guide. ; 2008.

18. Lord SR, Dayhew J: Visual Risk Factors for Falls in Older People. J Am Geriatr Soc 2001, 49:508-515.

19. Hiorth $\mathrm{YH}$, Lode K, Larsen JP: Frequencies of falls and associated features at different stages of Parkinson's disease. Eur J Neurol 2013, 20:160-166. 
20. Foley AL, Loharuka S, Barrett JA, Mathews R, Williams K, McGrother CW, Roe $\mathrm{BH}$ : Association between the Geriatric Giants of urinary incontinence and falls in older people using data from the Leicestershire MRC Incontinence Study. Age Ageing 2012, 41:35-40.

21. Clatworthy J, Buick D, Hankins M, Weinman J, Horne R: The use and reporting of cluster analysis in health psychology: a review. British journal of health psychology 2005, 10:329-358.

22. Everitt B: Cluster analysis. Chichester, West Sussex: [Hoboken, N.J.]: Wiley; 2011. ISBN 5th.

23. Cornell JE, Pugh JA, Williams JW Jr, Kazis L, Lee AFS, Parchman ML, Zeber J, Pederson T, Montgomery KA, Hitchcock Nokl P: Multimorbidity clusters: Clustering binary data from multimorbidity clusters: Clustering binary data from a large administrative medical database. Applied Multivariate Research 2009, 12:163-182.

24. Ward JH: Hierarchical Grouping to Optimize an Objective Function. Journal of the American Statistical Association 1963, 58:236-244.

25. SAS Institute Inc: SAS/STAT ${ }^{\circledR} 9.2$ User's Guide. Cary, NC. Cary, NC: SAS Institute Inc; 2008.

26. Hair JF, Black WC, Babin BJ, Anderson RE, Tatham RL: Cluster Analysis. In Multivariate data analysis. Volume 7th ed. Edited by Hair JF. Upper Saddle River, NJ: Prentice Hall; 2010.

27. Leipzig RM, Cumming RG, Tinetti ME: Drugs and falls in older people: a systematic review and meta-analysis: II. Cardiac and analgesic drugs. J Am Geriatr Soc 1999, 47:40-50.

28. Gribbin J, Hubbard R, Gladman JR, Smith C, Lewis S: Risk of falls associated with antihypertensive medication: population-based case-control study. Age Ageing 2010, 39:592-597.

29. Goldstein DS, Pechnik S, Holmes C, Eldadah B, Sharabi Y: Association between supine hypertension and orthostatic hypotension in autonomic failure. Hypertension 2003, 42:136-142.

30. Gangavati A, Hajjar I, Quach L, Jones RN, Kiely DK, Gagnon P, Lipsitz LA: Hypertension, orthostatic hypotension, and the risk of falls in a community-dwelling elderly population: the maintenance of balance, independent living, intellect, and zest in the elderly of Boston study. J Am Geriatr Soc 2011, 59:383-389.

31. Roig M, Eng JJ, Maclntyre DL, Road JD, FitzGerald JM, Burns J, Reid WD: Falls in people with chronic obstructive pulmonary disease: An observational cohort study. Respir Med 2011, 105:461-469.

32. Beauchamp MK, Hill K, Goldstein RS, Janaudis-Ferreira T, Brooks D: Impairments in balance discriminate fallers from non-fallers in COPD. Respir Med 2009, 103:1885-1891.

33. Beauchamp MK, Sibley KM, Lakhani B, Romano J, Mathur S, Goldstein RS, Brooks D: Impairments in systems underlying control of balance in COPD. Chest 2012, 141:1496-1503.

34. Faul AC, Yankeelov PA, Rowan NL, Gillette P, Nicholas LD, Borders KW, Deck S, Pariser D, Wiegand M: Impact of Geriatric Assessment and SelfManagement Support on Community-Dwelling Older Adults with Chronic Illnesses. Journal of Gerontological Social Work 2009, 52:230-249.

35. Tinetti ME, Speechley MR, Ginter SF: Risk factors for falls among elderly persons living in the community. The New England Journal of Medicine 1988, 319:1701-1707.

36. Campbell AJ, Reinken J, Allan BC, Martinez GS: Falls in old age: A study of frequency and related clinical factors. Age Ageing 1981, 10:264-270.

37. Prudham D, Evans JG: Factors associated with falls in the elderly: a community study. Age Ageing 1981, 10:141-146.

38. Fortin M, Hudon C, Haggerty J, Akker M, Almirall J: Prevalence estimates of multimorbidity: a comparative study of two sources. BMC Health Services Research 2010, 10:111.

39. Marengoni A, Rizzuto D, Wang H-X, Winblad B, Fratiglioni L: Patterns of Chronic Multimorbidity in the Elderly Population. J Am Geriatr Soc 2009, 57:225-230.

40. Vu T, Finch C, Day L: Patterns of comorbidity in community-dwelling older people hospitalised for fall-related injury: A cluster analysis. BMC Geriatrics 2011, 11:45.

41. Sturnieks DL, Tiedemann A, Chapman K, Munro B, Murray SM, Lord SR: Physiological risk factors for falls in older people with lower limb arthritis. The Journal of Rheumatology 2004, 31:2272-2279.

42. Volpato S, Leveille SG, Blaum C, Fried LP, Guralnik JM: Risk Factors for Falls in Older Disabled Women With Diabetes: The Women's Health and Aging Study. J Gerontol A Biol Sci Med Sci 2005, 60:1539-1545.
43. Stone CA, Lawlor PG, Savva GM, Bennett K, Kenny RA: Prospective Study of Falls and Risk Factors for Falls in Adults With Advanced Cancer. J Clin Oncol 2012, 30:2128-2133.

44. Cummings SR, Nevitt MC, Kidd S: Forgetting falls. The limited accuracy of recall of falls in the elderly. J Am Geriatr Soc 1988, 36:613-616.

45. Zieschang T, Schwenk M, Becker C, Oster P, Hauer K: Feasibility and accuracy of fall reports in persons with dementia: a prospective observational study. Int Psychogeriatr 2012, 24:587-598.

46. Greenberg SA: Analysis of Measurement Tools of Fear of Falling for HighRisk, Community-Dwelling Older Adults. Clin Nurs Res 2012, 21:113-130.

47. Bayliss EA, Ellis JL, Steiner JF, Main DS: Initial validation of an instrument to identify barriers to self-management for persons with co-morbidities. Chronic Illness 2005, 1:315-320.

doi:10.1186/1471-2318-14-22

Cite this article as: Sibley et al:: Chronic disease and falls in communitydwelling Canadians over 65 years old: a population-based study exploring associations with number and pattern of chronic conditions. BMC Geriatrics 2014 14:22

\section{Submit your next manuscript to BioMed Central and take full advantage of:}

- Convenient online submission

- Thorough peer review

- No space constraints or color figure charges

- Immediate publication on acceptance

- Inclusion in PubMed, CAS, Scopus and Google Scholar

- Research which is freely available for redistribution 